\title{
Theoretical research on the relationships between Aromatic ligands and spectroscopic properties of Pt(II) Complexes
}

\author{
baozhu yang ${ }^{1}$ and shuang huang ${ }^{1}$ \\ ${ }^{1}$ Changzhou University - Wujin Campus
}

January 24, 2022

\begin{abstract}
A series of cyclometalated platinum(II) complexes with aromatic ligands, such as pyridyl, pyrimidinyl and pyrazolate, were investigated with theoretical calculations. To investigate the relationship between ligands with molecular orbital, molecular rigidity, electroluminescent properties and spectroscopic properties, the electrostatic potential (ESP), density-of-states (DOS), root mean squared displacement (RMSD) were calculated. On the basis of calculated absorption and phosphorescence data, the analysis of "hole" and "electron" have also been performed. From the RMSD calculations, complex 3 shows significant structural distortions on S1 state and it may be applied in thermal activation delayed fluorescence (TADF) materials. The electroluminescent properties calculations show that complex 1 is suitable for hole transport material and complex 4 can be applied in electron transport material.
\end{abstract}

\section{Hosted file}

manuscript.docx available at https://authorea.com/users/457062/articles/553929-theoreticalresearch-on-the-relationships-between-aromatic-ligands-and-spectroscopic-properties-ofpt-ii-complexes 